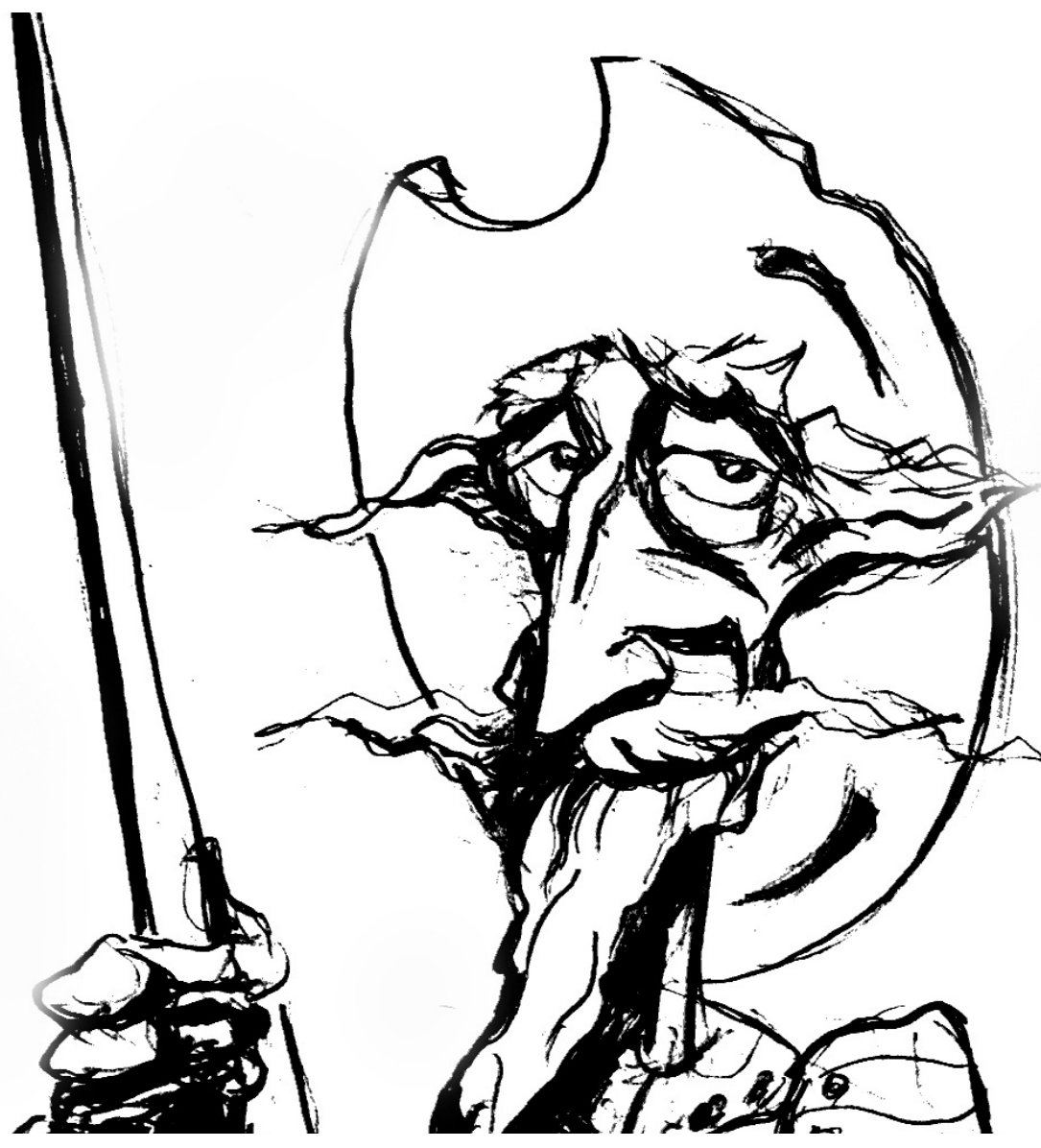

El nacimiento de la vejez y el envejecimiento en la Argentina durante la primera mitad del siglo XX. La contribución de los saberes demográficos, médicos y jurídicos

[Hernán Otero] 



\title{
El nacimiento de la vejez y el envejecimiento en la Argentina durante la primera mitad del siglo XX. La contribución de los saberes demográficos, médicos y jurídicos*
}

\author{
The Birth of Old Age and Aging in Argentina during the first half of the \\ Twentieth Century. The Contribution of Demographic, Medical and Legal \\ Knowledge
}

HERNÁN OTERO

\begin{abstract}
Resumen
El artículo aborda los saberes que confluyeron en la emergencia del envejecimiento y la vejez como temas de la agenda política y social. Para ello reconstruye la evolución de tres áreas disciplinares: la teoría del envejecimiento demográfico, introducida por el economista Alejandro Bunge; los saberes médicos sobre la vejez, y el lugar de los ancianos en el derecho hasta la sanción de los Derechos de la Ancianidad en 1948. El análisis se inicia en el siglo XIX pero centra su atención en la década de 1940, momento decisivo para la emergencia pública de la vejez y el envejecimiento como tema de agenda de las políticas sociales.
\end{abstract}

Palabras clave

Vejez; envejecimiento; demografía; medicina; derecho.

\begin{abstract}
The article addresses the knowledge that resulted in the emergence of aging and old age as issues on the political and social agenda. In order to do so, it analyses the evolution of three disciplinary areas: the theory of demographic aging, introduced by the economist Alejandro Bunge; the medical knowledge about old age, and the place of the elders in the law until the sanction of the Rights of the Elderly in 1948. The analysis begins in the nineteenth century but focuses its attention on the 1940s, the decisive moment for the public emergence of old age and aging as an issue on the agenda of social policies.
\end{abstract}

\section{Key Words}

Old age; aging; demography; medicine; law.

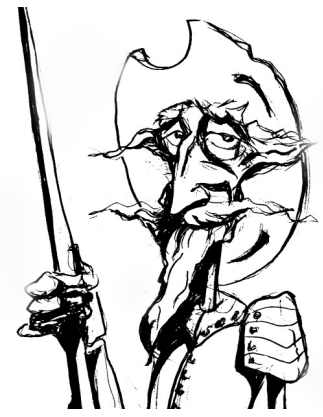

Recibido con pedido de publicación el 25 de agosto de 2019

Aceptado para su publicación el 31 de octubre de 2019

Versión definitiva recibida el 20 de diciembre de 2019

Hernán Otero, Instituto de Geografía, Historia y Ciencias Sociales, Consejo Nacional de Investigaciones Científicas y Técnicas, Universidad Nacional del Centro de la Provincia de Buenos Aires, Tandil, Argentina; e-mail: hernan.otero@conicet.gov.ar

\footnotetext{
* Agradezco las sugerencias y comentarios aportados por los evaluadores

Esta obra se publica bajo licencia Creative Commons. Atribución-NoComercial-CompartirIgual 4.0 Internacional

Otero, Hernán “El nacimiento de la vejez y el envejecimiento en la Argentina durante la primera mitad del siglo XX. La contribución de los saberes demográficos, médicos y jurídicos", Prohistoria, Año XXIII, núm. 33, jun. 2020, pp. 37-66.
} 
El siglo XX ha sido definido como el siglo de la vejez y el envejecimiento, caracterización en la que convergen hechos demográficos de gran envergadura y saberes científicos de disímil naturaleza y profundidad histórica. Los términos vejez y envejecimiento, por su parte, refieren a dimensiones diferentes pero que, con frecuencia, suelen asociarse entre sí. Mientras la vejez es una etapa del ciclo de vida, el envejecimiento puede denominar tanto ese proceso individual como el incremento de la proporción de personas ancianas dentro de una población, fenómeno conocido como envejecimiento demográfico. Aunque clara, la distinción entre la escala individual y la social resulta menos evidente en las etapas formativas de los saberes disciplinarios que estudian esos fenómenos, en los que influyen además concepciones morales y filosóficas de larga data.

Partiendo de esta constatación general, reconstruiremos aquí las principales representaciones científicas que abordaron la vejez y el envejecimiento. Como afirmó Phillipe Ariès (1983: 47), los límites heurísticos que dificultan el acceso a las prácticas sociales hacen que este tema suponga, más que ningún otro, el estudio de representaciones. A esas dificultades constitutivas del campo, se suma la escasez de estudios para el caso argentino, razón por la cual hemos optado por analizar de manera conjunta tres tipos de saberes: la teoría demográfica del envejecimiento, los saberes médicos, y los saberes jurídicos, de contornos más lábiles por su constitutiva imbricación con la política. Esta estrategia permite aumentar la densidad de referentes empíricos escasos y dispersos pero también proponer una comparación exploratoria entre disciplinas que suelen analizarse de manera aislada.

El texto se concentra en el período de cristalización inicial de los saberes sobre la vejez y el envejecimiento que va desde la aparición de Una nueva Argentina de Alejandro Bunge en 1940, primera explicitación sistemática de la teoría del envejecimiento demográfico en nuestro país, hasta la creación de la Sociedad Argentina de Geriatría en 1951, pasando por la declaración de los Derechos de la Ancianidad impulsados por Eva Perón en 1948. Estos tres hechos, emblemáticos en sus respectivos campos, suponen una reconstrucción histórica, de profundidad temporal variable en cada caso, atenta a apreciar más claramente las continuidades y rupturas. El presente artículo se articula, en suma, en tres partes, que abordanlos saberes mencionados, y unas conclusiones que buscan establecer sus similitudes y diferencias en dos aspectos básicos: el nivel de ruptura con los saberes previos y su contribución a la emergencia de la vejez y el envejecimiento como temas de progresiva importancia en la agenda científica y política. 


\section{El temprano desembarco del envejecimiento demográfico}

El envejecimiento demográfico, es decir el aumento de la proporción de personas mayores de determinada edad en la población total, es consecuencia de los dos componentes de la transición demográfica: la baja de la natalidad y la baja de la mortalidad. Las migraciones pueden jugar un rol relevante, como ocurrió en el caso argentino, dependiendo de la intensidad de los flujos y de la edad de los migrantes (Redondo, 2007). La generalidad de estos procesos explica que los censistas argentinos percibieran el fenómeno tempranamente, desde el censo nacional de 1914, antes de que el demógrafo francés Alfred Sauvy (1898-1990) presentara el texto fundador de la teoría (Sauvy, 1928-1929).

La figura esencial en la instalación del envejecimiento demográfico como problema fue el economista católico Alejandro Bunge (1880-1943), ${ }^{1}$ quien publicó en 1940 su célebre obra Una nueva Argentina. Dejando de lado sus ideas económicas, igualmente relevantes, Bunge realizó un sistemático análisis de los cambios demográficos experimentados por la Argentina desde 1914 hasta la década del cuarenta, entre los que destacaba la reducción del extraordinario crecimiento de la población, producida por la disminución de la inmigración internacional a partir de la Gran Guerra y por la caída de la natalidad, visible desde la década del treinta. Ambos fenómenos contribuyeron al clima de pesimismo demográfico que caracterizó al período y del que Bunge fue el más importante portavoz. ${ }^{2}$ Dado que la inmigración masiva dependía de las condiciones de los países de origen, Bunge se centró en las causas endógenas del crecimiento, es decir en la caída de la natalidad -o denatalidad según el neologismo francés de la época- que constituye la piedra angular de toda su argumentación.

En oposición a interpretaciones biologistas existentes en su época, Bunge consideró acertadamente a la caída de la natalidad como un problema de "orden moral", es decir derivado de la voluntad de las personas. Su interpretación incluía, además, una percepción perspicaz de la relación inversa entre niveles de bienestar y fecundidad y una crítica conservadora al mundo moderno en tanto portador de un individualismo materialista alejado del "concepto cristiano de la familia". La crítica a la "excesiva intervención de la mujer en todas las ramas del trabajo" (Bunge, 1984: 41 y 42) se inscribe en la misma secuencia argumental.

La baja de la natalidad constituía un problema por sus efectos sobre el crecimiento de la población, un tema de largo aliento para el poblacionismo argentino. A esta constatación, compartida por sus contemporáneos, se

\footnotetext{
${ }_{1}$ Para una perspectiva global sobre la vida y obra de Bunge ver, entre otros, González Bollo (2004, a y b).

2 Sobre el "pesimismo demográfico" del período de entreguerras, en el que se inscribe la obra de Bunge, ver Otero (2006); Reggiani y González Bollo (2007) y Biernat (2007).
} 
sumaron en Bunge dos aspectos específicamente demográficos vinculados con la reproducción diferencial de las clases sociales y con el envejecimiento de la población. En el primer caso, la menor fecundidad de las clases medias y altas implicaba el aumento proporcional de la descendencia de los sectores más pobres, reproducción diferencial que explicaba también el aumento de la ilegitimidad de los nacimientos, fenómeno de mayor incidencia precisamente en los sectores humildes. Estas constataciones resultaban de mayor gravedad por la adhesión de Bunge a la eugenesia como lo ilustra su temor al "creciente predominio numérico de los débiles corporales y mentales" (Bunge: 1984, 26). De tal suerte, la caída de la natalidad representaba un problema tanto cuantitativo (reducción del crecimiento demográfico) como cualitativo (degradación por mayor fecundidad de los menos aptos). Si bien el uso del término "raza" durante esos años es impreciso, cuando no puramente metafórico o descriptivo, Bunge acepta aspectos básicos del universo eugenésico como el supuesto de que la inteligencia es hereditaria y la idea, de gran influencia entonces, de que la raza blanca se encamina hacia el "doble drama" de la reducción numérica y la selección inversa. ${ }^{3}$

En segundo lugar, Bunge observó que la caída de la natalidad implicaba el aumento proporcional del número de personas mayores, es decir lo que se conoce como envejecimiento de la población por la base de la pirámide, perceptible ya en el censo porteño de 1936 en el que la proporción de personas de 60 años y más había trepado al 6,3\%. El envejecimiento de los grupos migratorios (analizado en detalle para los italianos), de considerable impacto en la población total, no hacía más que acentuar el fenómeno en razón de la ya mencionada reducción de la inmigración europea.

Pero además de percibir y medir el fenómeno, Bunge avanzó las principales razones que lo convertían en un problema demográfico cargado de consecuencias negativas. En su visión, el envejecimiento constituía un problema por razones esencialmente económicas entre las que destacó la relación de dependencia, tanto en términos micro (es decir al interior de las familias) como macro demográficos. Si bien no utiliza ese indicador, la lógica es la misma como lo muestra la siguiente cita: "En el conjunto de la sociedad cinco o seis hombres sostienen hoy un reducido número de niños y algún anciano. ¿Puede pedírseles que imaginen desde ahora el inquietante cuadro que ha de presentarse más tarde a esos pocos niños, cuando al llegar a la edad productiva deban sostener a

\footnotetext{
3 "De un golpe se coloca la raza blanca en las dos pendientes. Prepara su irremediable descenso numérico y se encamina a la selección inversa. El número creciente de los menos dotados amenaza sobreponerse al número creciente de los más selectos" (Bunge, 1984: 49). El propio Bunge admite que es más difícil de probar la segunda de las proposiciones (efectos hereditarios de la reproducción diferencial), razón por la cual recurre a autoridades como Alexis Carrel (autor del best seller L'homme, cet inconnu, de gran influencia en los ambientes de médicos católicos argentinos) y el eugenista norteamericano Theodore Stoddard.
} 
varios hombres o mujeres de edad avanzada?" (Bunge: 1984: 26). El deterioro de la relación de dependencia tendría su impacto más evidente en las jubilaciones, que se universalizaron durante las décadas del cuarenta y del cincuenta. Si bien el argumento se halla poco desarrollado, Bunge consideraba a los ancianos como una carga creciente sobre un número cada vez menor de "espaldas", una imagen clásica de la propaganda natalista francesa del período. Más llamativa resulta la afirmación de que las jubilaciones constituyen un "inmoral y antipatriótico ideal de "vivir sin trabajar'” y su caracterización a partir de las visiones negativas sobre el empleo público. ${ }^{4}$

La argumentación económica, basada en el concepto de carga,se reforzaba con imágenes clásicas del modelo deficitario de la vejez que enfatizan tanto el carácter improductivo de los mayores como la asociación entre vejez y enfermedad:

"Los asilos empezarán a requerir nuevos pabellones. La parte de recursos de los que producen, aplicada alos que han superado la edad de producir, será cada vez mayor. En el segundo acto del drama, con la madera de las cunas olvidadas y de los bancos escolares vacantes habrá que construir sillones para los hombres y las mujeres inevitablemente retirados del trabajo por su edad. Las ruedas de los abandonados coches de bebés ausentes, se requerirán para las sillas rodantes de los muchos ancianos [...] repletos los asilos habrá que habilitar a tales fines las escuelas sin niños y las fábricas sin obreros..." (Bunge, 1984: 27).

Bunge imagina asimismo efectos negativos sobre aspectos económicos como el consumo y las cajas jubilatorias pero también consecuencias amplias aunque imprecisas- en el plano de las relaciones sociales. ${ }^{5}$ Como puede observarse, las consecuencias del envejecimiento enunciadas por Bunge remiten tanto a aspectos potencialmente verificables como a prejuicios sobre los viejos (que la literatura especializada define como "viejismo") sobre cuya validez estadística el autor no puede dar cuenta.

\footnotetext{
${ }^{4} \mathrm{El}$ argumento de las jubilaciones es desarrollado en la segunda parte de un artículo ("Más peso sobre menos espaldas") publicado el $1^{\circ}$ de octubre de 1940 como parte de una dura crítica al empleo público. Esa segunda parte fue reproducida en el último capítulo de Una nueva Argentina (Bunge, 1984: 517-519).

${ }^{5}$ Por ejemplo, "habrán de diferir las normas para el futuro ante la perspectiva de menor número de niños y mayor de ancianos". En una sola ocasión menciona los efectos negativos del envejecimiento sobre la capacidad militar de la Nación, argumento frecuente en la demografía europea del período: "Se notarán raleadas las filas de los que van alcanzando la edad de armas llevar y la de empunar el martillo, el arado, o los instrumentos de las ciencias o las artes" (Bunge, 1984: 108 y 27, respectivamente).
} 
Si bien la exposición de las consecuencias del envejecimiento es relativamente escueta, no ocurre lo mismo con la medición de su peligro potencial, como lo ilustran sus célebres proyecciones de población. Como es sabido, Bunge conjeturó que la población del país experimentaría una disminución drástica de su crecimiento, producida por la reducción de la natalidad y de los flujos migratorios, fruto del estancamiento de la economía argentina desde la Gran Guerra. A partir de la información disponible, Bunge observó que el crecimiento de la población se había reducido paulatinamente a partir de 1914 hasta alcanzar niveles alarmantes en 1939 (crecimiento de 12,7 por mil habitantes). La más favorable de sus estimaciones suponía que si la caída de la natalidad se detenía y el saldo migratorio se mantenía igual al de los años precedentes, el país llegaría a tener 20 millones de habitantes en 1988. La hipótesis menos favorable, pero que el autor consideraba como "quizás la más probable" (Bunge, 1984: 34), conjeturaba que si la fecundidad del interior descendía hasta los niveles de la capital y si la de esta jurisdicción no continuaba bajando, la población aumentaría lentamente hasta 1960 (máximo de 15 millones en 1958), para caer a 11,5 millones en 1988.

Además de la población total, Bunge proyectó también la estructura por sexo y edad a partir del censo de 1914, de una tabla de mortalidad para ese año, y de la utilización de dos hipótesis sobre la inmigración internacional. Mientras la primera hipótesis supone que la inmigración no tiene ningún impacto y que la natalidad no sería inferior a la de 1938, la segunda incorpora una inmigración del orden del 1 por mil de la población total, es decir similar a la de los años precedentes (Bunge, 1984: 114). Puestas a funcionar, ambas hipótesis mostraban una etapa de maduración y luego el envejecimiento a gran escala, señal inequívoca de la "catástrofe demográfica". Según sus cálculos, la población de 60 años y más pasaría de casi 7\% en 1938 a 19,9 y 12,2\% en 1988, según la primera y segunda hipótesis respectivamente. De modo previsible, la incorporación de la inmigración (segunda hipótesis) reduce la proporción de mayores de 60 años en el total de la población en 8 puntos porcentuales como así también la diferencia entre el envejecimiento femenino y el masculino (la distancia entre ambas proporciones en 1988 es de 2,5\% en la primera hipótesis contra 1,6 en la segunda hipótesis, siendo más numerosas las mujeres en ambos casos debido a la mayor mortalidad masculina). ${ }^{6}$

Como es sabido, la evolución posterior alejó los temores de las proyecciones bungeanas ya que la Argentina superó los 32 millones de habitantes hacia 1990, en lugar de los escasos 11.500 .000 previstos. Lo mismo

\footnotetext{
${ }^{6}$ Bunge utiliza diferentes umbrales para definir a la población vieja: 55 años cuando se refiere discursivamente al peso de las jubilaciones, 50 en el caso del envejecimiento de los inmigrantes y 60 en las proyecciones. Si bien no explicita las razones, puede conjeturarse que las diferencias obedecen tanto a los datos disponibles como a la inexistencia en la época de criterios estandarizados, que serían definidos por Naciones Unidas en la década del cincuenta.
} 
ocurrió con la población mayor de 60 años que recién superó el $7 \%$ en el período intercensal 1947-1960 mientras que para Bunge lo haría (y con valores superiores al 9\%) para 1948. Desde luego, no corresponde evaluar las proyecciones de población en términos de verdad o falsedad ya que los métodos de estimación solo indican qué pasará con una población a partir de determinados supuestos. Más claro aún, no todas las proyecciones pretenden ser una "previsión" sobre lo que efectivamente sucederá. Ello no impide la existencia de problemas heurísticos y de interpretación (la relación entre la caída de la natalidad y la despoblación dista del automatismo que le adjudica Bunge si no se incorpora el estudio más sistemático de la mortalidad, por ejemplo) sobre los que no podemos detenernos aquí. ${ }^{7}$

Otro argumento relevante es que las proyecciones de Bunge tenían por objetivo analizar las consecuencias negativas de la baja de la natalidad y, sobre todo, prevenir mediante políticas concretas que tales escenarios dramáticos ocurrieran. Siguiendo esa clave, sus estimaciones alarmistas eran un típico ejemplo de la profecía que busca destruirse a sí misma, es decir de la máxima de Alfred Sauvy "prever para no ver". Se trata de una operación más política que científica en la que la proyección representa una meta a lograr o a evitar. Cualquiera sea el caso, es muy relevante que Bunge buscara probar los efectos negativos de la denatalidad y el envejecimiento mediante una proyección, operatoria también presente en el texto fundacional de Sauvy, señal inequívoca del peso que tenían para entonces las simulaciones estadísticas. Con todo, la argumentación bungeana, al igual que la de sus contemporáneos de otras latitudes, fue mucho más allá de los posibles escenarios futuros aportados por las estimaciones.

Las evoluciones previstas planteaban, como vimos, dos riesgos: la despoblación causada por la denatalidad y el predominio creciente de los débiles mentales, a través de un "drama en dos actos": primero, la denatalidad, "absolutamente inevitable", y luego el envejecimiento. De no mediar acciones en contrario, "el tercero [de los actos] sería la muerte" (Bunge, 1984: 28). Conforme a una amplísima tradición argumental, la imagen de la muerte final de la sociedad fue reforzada en la semántica gráfica por la continua referencia a las pirámides con forma de "urna funeraria". ${ }^{8}$

\footnotetext{
7 Sobre la distinción entre previsiones, perspectivas y proyección ver: Henry (1987). Una reflexión comparativa de las proyecciones de Bunge con las de autores precedentes en: Otero (2004).

8 Existen dos tipos de pirámides "representativas, del vigor demográfico la una y de la decadencia la otra. El pueblo que debe ser representado por la urna funeraria lleva en su interior la muerte". En sentido análogo, refiere a la asociación, de corte epidemiológico, entre invasión y muerte: "Ninguno de los países de América se exceptúa. El mal invade primero a Estados Unidos, después a la Argentina y luego a los demás. Empieza por las grandes ciudades
} 
Como lo ha mostrado Le Bras (1991), las primeras versiones de la teoría del envejecimiento mezclaban dos secuencias de diferente naturaleza pero unidas en una argumentación de alto impacto pedagógico. En primer lugar, una secuencia operacional y estadísticamente verificable (el aumento de la proporción de personas mayores de determinada edad), de la que pueden derivarse efectos sociales y económicos potencialmente verificables. En segundo lugar, una secuencia filosófica, más puramente ideológica, que asocia el envejecimiento de la población con la decadencia y muerte de una sociedad. Esta segunda secuencia, de imposible sustento estadístico, se basa en una homologación indebida entre el envejecimiento individual, que termina con la muerte biológica, y el envejecimiento de una sociedad en la que la asociación con la muerte carece desentido.

Esta segunda secuencia deriva de concepciones filosóficas de la época relativas, como vimos, a la decadencia de la raza blanca. Si bien se trataba de concepciones de muy amplia difusión e impacto en ámbitos diversos, alcanzaron su mayor influencia en las corrientes natalistas de corte nacionalista, como ocurrió en el caso francés. Como es sabido, tras la derrota en la guerra franco-prusiana de 1870, Francia desarrolló una corriente antimalthusiana, poblacionista y natalista que consideró a la denatalidad como la principal causa de los problemas sociales y económicos del país. En esa saga se destacó la Alliance nationale pour l'accoissement de la population française, creada en 1896. La activa propaganda natalista de esta organización encontró su punto de culminación y su principal arma de combate en las vertientes más alarmistas de la teoría del envejecimiento, como ocurre en la obra de Fernand Boverat (18851962), activo miembro de la Alliance y principal difusor de la teoría del envejecimiento durante las décadas de 1930 y $1940 .{ }^{9}$

Los diagnósticos de Bunge confluyeron en un conjunto de propuestas, decuño conservador por su crítica a las transformaciones del mundo moderno como la urbanización y el trabajo femenino. El aumento de la natalidad remitía también a una pérdida de confianza en el aporte migratorio europeo visto (a diferencia de sus interpretaciones optimistas de principios del siglo) como poco sustantivo en términos cuantitativos y complejo en el plano cualitativo, debido a la necesidad de alcanzar una "rápida y acabada fijación" de la "fisonomía racial argentina" mediante los matrimonios mixtos y el "crisol de razas". ${ }^{10}$

y va extendiéndose por las menores, para invadir más tarde a las regiones rurales" (Bunge, 1984: 29).

${ }^{9}$ El libro de Boverat (Le vieillissement de la population) fue publicado en 1946. La mejor exégesis sobre la teoría del envejecimiento en Francia sigue siendo Bourdelais (1997).

${ }^{10}$ La ideas políticas de Bunge (nacionalismo católico, defensa de la hispanidad, visión corporativista y castrense de la sociedad), sobre las que no podemos detenernos aquí, se perciben mejor en el capítulo XX ("La defensa del país"). Sobre las relaciones entre el catolicismo y la eugenesia latina ver Vallejo y Miranda (2014). 
Volviendo a nuestro tema, puede postularse que, al igual que en Europa, los desarrollos sobre el envejecimiento constituyen en Bunge un argumento complementario, de gran eficacia pedagógica, de su preocupación central que es la caída de la natalidad. Una evidencia suplementaria sobre la importancia del argumento natalista son las numerosas referencias a los autores que analizaron la fecundidad y el llamativo silencio sobre los teóricos del envejecimiento, aunque su obra demuestra que conocía los argumentos de ese campo discursivo. Sin embargo, a diferencia de los pensadores de los que extrae sus ideas en un clásico proceso de difusión científica centro-periferia, Bunge exagera las similitudes al no incorporar las diferencias sustantivas entre el escenario europeo y el contexto argentino. Dos diferencias se destacan nítidamente en tal sentido. Por un lado, los devastadores efectos que la Gran Guerra produjo en la demografía de países como Francia, con la consecuente pérdida de jóvenes y el aumento proporcional de los ancianos. Por otro, el avance del nazi-fascismo en el conflictivo escenario europeo que aumentó la centralidad de las cuestiones de población al incorporarlas más plenamente al engranaje del poder estatal y de la geopolítica internacional.

Cabe destacar por último que la obra de Bunge, concebida por él mismo como "destinada a los dirigentes de nuestro país y a la juventud estudiosa", gozó de amplia difusión en la época gracias a la publicación de sus textos en diarios de gran circulación. Sus tesis fueron retomadas, por ejemplo, en el censo nacional de población de 1947, que adhiere a muchos argumentos de la interpretación bungeana, en particular los relativos a la caída de la natalidad y al envejecimiento demográfico como un "mal grave", si bien los censistas se despegan del "pesimismo de sus pronósticos" (República Argentina, 1952: I: XXXVII, XLI, respectivamente).

\section{La larga marcha de los saberes médicos}

La teoría del envejecimiento demográfico desembarcó rápido en la Argentina debido a que las realidades locales ofrecían pruebas palpables sobre la pertinencia de esos saberes pero también porque había contactos intelectuales y científicos fluidos con los países centrales, una constatación mayoritaria en los estudios disponibles sobre disciplinas científicas.

En el caso de la medicina, aunque las reflexiones sobre la vejez comienzan tempranamente en la Antigüedad clásica, la idea de que algunas enfermedades son específicas de determinadas edades se abrió paso recién durante el siglo XVIII. Ello no impidió la existencia de saberes previos que suministraban consejos sobre los cuidados a tener en esa edad, como el mantener cierta higiene de vida (en particular, la sobriedad en la alimentación y los placeres), consejos que dieron lugar a una abundante literatura llamada entonces gerocómica. También durante esa centuria se desarrolló, de manera 
más lenta, la idea opuesta a la anterior, según la cual el ser humano debe mantenerse dinámico en la medida de sus posibilidades, germen de la teoría actual del envejecimiento activo (Gutton, 1988: 156-158). ${ }^{11}$

La reflexión moderna sobre la vejez como una etapa del ciclo de vida que plantea problemas médicos y sanitarios específicos, distintos al resto de las edades, es en cambio reciente en la historia, como lo testimonia el surgimiento, casi simultáneo, de la gerontología y la geriatría durante la primera década del siglo XX. La gerontología, es decir el estudio científico del envejecimiento desde una perspectiva no exclusivamente médica, apareció en 1903 con los estudios, en Paris, del influyente especialista ruso Elie Metchnicoff (1845-1916), mientras que la geriatría, concentrada en los aspectos médicos y biológicos de la vejez, lo hace en Estados Unidos en 1909, gracias al austríaco Ignaz Nascher (1863-1944). La emergencia de estos saberes fue posible gracias a los avances operados en el siglo XIX en Francia, Estados Unidos y Gran Bretaña.

En Francia, por ejemplo, los manuales de medicina incluyen textos sobre enfermedades de viejos desde la década de 1830 (las revistas especializadas, como la Gazette médicale de Paris, lo harán un poco más tarde), con especial referencia a las génito-urinarias, las afecciones circulatorias, la neumonía y la tuberculosis, los problemas articulares y óseos, y la demencia senil. ${ }^{12}$ Si bien en ocasiones, como en el caso de las cataratas, las enfermedades de la vejez dieron lugar a progresos médicos relevantes, la terapéutica no se diferenciaba demasiado de los siglos precedentes, como lo muestra la insistencia en los consejos de continencia y templanza. El aumento de los viejos en los hospicios contribuyó asimismo al desarrollo de estudios en profundidad como los de Jean-Martin Charcot (1825-1893) en la Salpetrière (Gutton, 1988: 238-240). A pesar de ello, la medicina francesa de la vejez tuvo un retraso considerable en comparación con los ingleses, alemanes y estadounidenses. Según Bourdelais (1997: 388), el retraso francés durante la primera mitad del siglo XX derivó de la preocupación por la caída de la natalidad que habría contribuido a fortalecer la investigación en áreas médicas consideradas más prioritarias como la salud de las madres y los niños. ${ }^{13}$

\footnotetext{
${ }^{11}$ Dejando de lado la Edad Media, durante la cual el viejo recibió poca atención, se destacan como períodos de reflexión más fructífera la Antigüedad clásica y el Renacimiento, momento en el que se reactualizaron las recomendaciones de Galeno sobre la vejez. Sobre la historia de los saberes médicos relativos a la vejez ver Bourlière (1979), Sánchez Granjel (1999) y Carbajo Vélez (2008).

${ }^{12}$ Las enfermedades mentales fueron más estudiadas en relación a los niños que a los viejos debido a sus potenciales efectos sobre la delincuencia. Ver por ejemplo los análisis relativos a la Liga Argentina de Higiene Mental, creada en 1929, en Cesano (2016: 106-109).

${ }^{13}$ Según Feller (2005: 89-120) el "largo eclipse" de la geriatría en Francia (evidenciado en el tardío surgimiento de la Societé Française de Gérontologie y la Fondation Nationale de Gérontologie en 1960 y 1967, respectivamente) se explica por el temor generado por el envejecimiento demográfico, hipótesis coincidente con la de Bourdelais (1997).
} 
Iniciada en Estados Unidos, la geriatría se desarrolló con rapidez en Gran Bretaña a partir de la década de 1930, aunque en lugar subordinado y no muy bien visto por la profesión médica, difusión que, según Thane (2007: 27), se habría debido al aumento de la proporción de ancianos y al éxito de algunos tratamientos como las embolias. Entre otros, merecen destacarse los trabajos sobre el envejecimiento biológico del ruso Vladimir Korenchevsky (1880-1959) en el Instituto de Investigaciones Médicas en Londres, quien fue además fundador de la Bristish Society for Reserchon Ageing. A partir de la década del cincuenta, se produjo el despegue de la gerontología social, impulsado en los Estados Unidos por problemáticas tales como el aislamiento y los prejuicios etarios que afectan a las personas mayores (Sánchez Salgado, 2005: 77).

Más allá de especificidades nacionales en otros planos, una constatación se impone en todos los países: la geriatría se desarrolló mucho más tardíamente que la pediatría y la ginecología tanto por el interés social acordado a la reproducción humana y a la salud de los niños, como por el mayor prestigio que esas áreas conferían a los sectores médicos. Incluso a pesar de la creación de organismos como la International Association of Gerontology en 1950 y de desarrollos crecientes a partir de esa década, los estudios sobre la vejez seguirán teniendo un rol mucho menos prestigioso que otras especialidades médicas.

En mayor medida que en Francia, la reflexión sobre la vejez en la Argentina tardó en abrirse paso entre las especialidades médicas. El análisis de las tesis de medicina de la Universidad de Buenos Aires, usadas como indicador privilegiado de los avances de ese campo, ${ }^{14}$ muestra que la primeras tesis consagradas a enfermedades ocurridas sobre todo "en la vejez", como el síndrome ulceroso o la pneumonía, datan recién de la segunda mitad de la década de 1910, exceptuando una tesis de 1887 que se orienta a los aspectos legales. ${ }^{15}$ Hasta la década del veinte, las tesis de medicina o bien carecen de una adscripción etaria particularo bien se refieren masivamente a las edades iniciales de la vida. Ello explica la abundancia de tesis sobre embarazo, aborto,

\footnotetext{
${ }^{14}$ Las revistas médicas son otra fuente que apela por estudios sistemáticos en relación a la vejez. Otra literatura de interés, sobre la que no podemos detenernos aquí, es la que expone "la mejor forma de envejecer", género de largo aliento desde Cicerón y Séneca hasta la literatura actual de autoayuda.

${ }^{15}$ Nos referimos a las tesis de César Rómulo, Síndrome ulceroso en los viejos (Casa Editora Vitullo Osorio Hnos, Buenos Aires, 1918, 87 pp.) y de Nicolás Bergalli, Contribución al estudio clínico de la pneumonía en el viejo (Librería "Las Ciencias", Casa Editora e Imprenta de A. Guidi Buffarini, Buenos Aires, 1915, 125 pp.). Esta última, a pesar de su título, no va más allá de la constatación poco novedosa en la época de que se trata de una enfermedad más frecuente en la vejez y del reconocimiento de "la poca eficacia de la terapéutica en el viejo pneumónico". La tesis de 1887 corresponde a Alejandro V. Murguiondo, La infancia y la vejez ante la medicina legal (Buenos Aires, Tipografía La Capital, 1887, 98 pp.) que adhiere a la idea de que los hijos de ancianos (al igual que los de alcohólicos, prostitutas, consanguíneos, etc.) forman parte del grupo de niños degenerados (p. 54). Sobre las tesis del período 1827-1919 ver Candiotti (1920).
} 
parto e infección puerperal y sobre dolencias "en la infancia" (hernias, desarreglos intestinales, diarreas, influenza, convulsiones, asfixia, enteritis, gripe, parálisis, tuberculosis, etc.). Lo mismo ocurre con aspectos más generales como la mortalidad de los expósitos, la mortalidad infantil, la dentición, la alimentación, la obesidad, la lactancia, la higiene o el ejercicio durante esa etapa. Ello no implica que no haya referencias, en general muy escasas, a los viejos en tesis que analizan enfermedades de mayor frecuencia en edades avanzadas (como el reumatismo, la prostatitis, el Parkinson, las cataratas, etc.) pero sí que la vejez, como fase que amerita un estudio autónomo, aparece recién durante el siglo XX. Incluso muchas tesis que analizan enfermedades más frecuentes con el aumento de la edad, no lo hacen tomando esa circunstancia de modo prioritario. ${ }^{16}$ Otro rasgo a destacar, aunque no sorprendente, es que las tesis analizan aspectos básicamente biológicos con poca atención a los factores sociales.

Sobre un total de 3.860 tesis de medicina correspondientes al período 1821-1919 solo tres (0.1\%) se refieren específicamente a la vejez. ${ }^{17}$ Tesis como la de Enrique Fóster, El niño (1902), o la de Adela Zauchinger, La protección a la primera infancia (1910), carecen de equivalentes referidos a la vejez, que es tratada en el marco indiferenciado de las enfermedades del mundo adulto. Este panorama no cambia de manera substantiva entre 1920 y 1955 a pesar del aumento considerable del número de tesis (4.143 en medicina y 521 en farmacia). En un contexto en el que las tesis devienen más específicas (análisis de enfermedades desde un punto de vista clínico), las relativas a la vejez siguen siendo escasas (una docena en total) y refieren sobre todo a demencia senil, diabetes, hipertensión arterial, osteoporosis y tuberculosis. La primera tesis sobre geriatría corresponde recién al año 1947. Por el contrario, las tesis sobre infancia se multiplican, sobre todo durante los treinta y cuarenta, y aparecen incluso tesis relativas a la adolescencia. ${ }^{18}$

\footnotetext{
${ }^{16}$ A título de ejemplo, Juan H. Videla, Enfermedad de Parkinson (Parálisis agigante), 1885, 48 pp.; Eliseo Verón, Operaciones en la catarata y observaciones clínicas (Buenos Aires, Imprenta de M. Biedma, 1876); Juan Rabuffetti, Prostatitis y peri-prostatitis agudas (Buenos Aires, Imprenta y Casa Editora de Agustín Etchepareborda, 1902, 107 pp.). Esta última tesis, de considerable mejor calidad que el promedio, presta más atención a la edad.

${ }^{17}$ La comparación con el caso francés puede ser ilustrativa. Aunque existen capítulos sobre enfermedades de la vejez en los manuales, ninguna de las tesis de medicina de la Academia de Paris abordó el tema de manera específica entre el fin del Imperio y 1858; la proporción aumentó al 1\% a partir de 1876, pero era aún inferior al 2\% en vísperas de la Segunda Guerra Mundial (Bourdelais, 1997: 362).

${ }^{18}$ A título de ejemplo, Marcos Carrión, Algunas consideraciones sobre la demencia senil y sus formas clínicas, 1920, 71 pp.; Braulio Moyano, Demencia senil y demencias preseniles, 1932, 82 pp.; Juan Etchepareborda, Diabetes en los viejos, 1935, 60 pp.; Enrique Gómez Arévalo, La erisipela en los mayores de 50 años, 1943, 132 pp., Cecilia Sosin, Osteoporosis senil, 1943, 38 pp.; Rodolfo Pizarro, La tuberculosis pulmonar después de los 50 años de edad en el sexo masculino, 1944, 38 pp., y Mauricio Doctorovich, Conceptos sobre geriatría, 1947, 56 pp.
} 
Otro indicador de interés son las causas de mortalidad de los registros de defunción, aunque aquí las mediaciones son mayores ya que la definición precisa de la causa de deceso por parte de profesionales fue un proceso largo y difícil, sobre todo en las zonas rurales. ${ }^{19}$ Desde fines del siglo XIX, la clasificación internacional de causas de muerte dio lugar a un debate recurrente entre quienes proponían incluir a la "debilidad senil" (o sinónimos como "vejez", "senectud", etc.) como una causa aceptable de muerte y quienes la consideraban como un caso de diagnóstico erróneo que debía formar parte de las "causas mal definidas". Para los partidarios de la primera vertiente, el debate suponía asimismo una reflexión sobre la edad a partir de la cual la vejez podía ser invocada como causa de muerte. Esta segunda interpretación se fue imponiendo aunque la evolución no fue lineal ni automática: la vejez desapareció en la cuarta revisión internacional de causas de muerte de 1929, fue reintroducida en la revisión siguiente (1938) y suprimida en la octava revisión de 1965 (Bourdelais, 1997: 242-245). El análisis del caso argentino durante el período que nos ocupa muestra dos aspectos de interés. Por un lado, que las causas equiparables a la vejez (como decrepitud y senectud) tuvieron un peso muy pequeño en el total de defunciones ya que pasaron del $0,6 \%$ en 1860 1863 al 1,1\% en 1952 (año en que estaba aún vigente la nomenclatura de 1938), incremento imputable en parte al aumento de la proporción de ancianos. La baja proporción de la causa vejez no supone, sin embargo, una definición precisa de las defunciones ya que las causas mal especificadas (51,5\% en 18601863 ) eran todavía altas $(15,8 \%)$ en $1952 .{ }^{20}$ En segundo lugar, la vejez fue eliminada como causa en la clasificación utilizada en 1948 (año en que pasó a formar parte del grupo de mal definidas), es decir casi dos décadas antes de la octava revisión internacional de 1965.

La psicología es otra de las áreas en la que puede apreciarse la imagen del viejo. Si bien no hay estudios sobre el particular, el célebre texto de José Ingenieros (1877-1925), El hombre mediocre, publicado por primera vez en $1913 \mathrm{y}$ de notable difusión desde entonces da pistas de interés. El planteo de Ingenieros, sintetizado en el título del capítulo "La vejez niveladora", define a la vejez como una etapa de nivelación hacia abajo de las capacidades físicas, intelectuales y morales de los seres humanos. Basado en autores del período pero también en simples prejuicios, Ingenieros sostiene que "la decadencia del hombre que envejece está representada por una regresión sistemática de la intelectualidad. ${ }^{21} \mathrm{Al}$ principio, la vejez mediocriza a todo hombre superior; más

\footnotetext{
${ }^{19}$ Para un análisis de caso, ver Otero (2017) donde se muestra que la causa vejez era usada sobre todo para las edades más altas (75 años y más).

${ }^{20}$ Los datos provienen de Hudson (1865) y República Argentina (1956).

${ }^{21}$ Sus principales referencias son el psicólogo francés Théodule-Armand Ribot (1839-1916), (en particular Ribot, 1900) y el crítico literario, de igual nacionalidad, Auguste Faguet (1847-1916). Ingenieros critica frontalmente a este último por pedir más respeto hacia los viejos, a pesar de que su obra La vieillesse (Faguet, 1926) es extremadamente crítica sobre la vejez.
} 
tarde, la decrepitud inferioriza al viejo ya mediocre. Tal afirmación es un simple corolario de verdades biológicas" (Ingenieros, 2006: 128). Además de aspectos biológicos, sobre los que no se detiene mayormente, caracteriza a la vejez a partir de signos negativos de orden moral como la rutina, la pérdida de la ternura o, en clave ciceroniana, la avaricia. A ello se suman la "analgesia moral", la hostilidad hacia las innovaciones y hacia los jóvenes (el "odio oculto por todas las fuerzas vivas que crecen y avanzan, un sordo rencor contra todas las primaveras"), las "ideas obsesivas absorbentes", la perdida de sentimientos altruistas, las "convicciones inmutables" y la "inadaptación al medio moral". Este cuadro negativo se completa con otras dos ideas frecuentes en la época. En primer lugar, la vejez como una regresión a "la mentalidad del mediocre, del niño y del salvaje" (Ingenieros: 2006: 129), tributaria de la asociación entre la infancia y la senectud, un lugar común de la literatura desde la Antigüedad. En segundo término, la idea de que las creaciones rutilantes de la ciencia y el arte ocurren a edades tempranas para lo cual cita una serie de casos que confirmarían esa hipótesis, parcial y variable según las disciplinas consideradas. La construcción de Ingenieros incluye asimismo una lectura política según la cual los jóvenes representarían el cambio revolucionario (como lo ilustrarían las revoluciones americana y francesa) mientras que la vejez conduciría al conservadurismo.

Si bien Ingenieros está en lo cierto cuando postula la caída de las funciones físicas y mentales con el aumento de la edad sorprende que extienda los atributos de la llamada vejez extrema (lo que hoy se define como cuarta edad) a la vejez como un todo indiferenciado. Aunque no analiza la edad de inicio de la vejez, una referencia al pasar muestra que adhiere a la idea, común en la época, de fijar su umbral en los 60 años. ${ }^{22}$ Pero más allá de extender hacia abajo y sin precauciones rasgos propios de la fase terminal de la vejez, llama la atención que no mencione ningún rasgo positivo en esa edad (la consabida referencia a la experiencia, por ejemplo), algo frecuente en la reflexión sobre el tema cuanto menos desde la tradición greco-romana.

La más temprana e intensa preocupación por la infancia que por la vejez, evidenciada por las tesis de medicina, replica el desfasaje, igualmente marcado, en la emergencia de las sociedades científicas abocadas a esos grupos de edad. La Sociedad Argentina de Pediatría (SAP), por ejemplo, fue fundada a instancias del célebre médico Gregorio Aráoz Alfaro en 1911 lo que la convirtió en una de las más antiguas del mundo. Homólogas como la Société Française de Pédiatrie y la American Academy of Pediatrics fueron fundadas en 1929 y 1930, respectivamente (SAP, 2011). ${ }^{23}$ La Sociedad Argentina de Gerontología y Geriatría

22 "El que esto escribe hoy, creerá, probablemente, lo contrario cuando tenga más de sesenta años" (Ingenieros, 2006: 130), probabilidad que no alcanzó a verificar ya que murió a los 48 años.

${ }^{23}$ Sobre la pediatría en la Argentina ver Rustoyburu (2019: 40-46). 
(SAGG), por su parte, fue creada en 1951, a instancias de un grupo de médicos reunidos en torno al Dr. Ernesto Röttjer, solo seis años después de la Gerontological Society of America (1945) y tres de su homónima española (1948), siendo además la primera de Latinoamérica. Otros hitos importantes de la SAGG fueron la creación de la revista Geriatría, la realización de las primeras jornadas de la especialidad en 1954 y la incorporación a la Asociación Internacional de Gerontología en 1957, pocos años después de la creación de ese organismo en Lieja (1950). Al igual que en otros contextos, el desarrollo de los enfoques más sociales de la gerontología ocurrirá con posterioridad a nuestro período. Durante la década del setenta aparece la psicogeriatría y se incorporan nuevos profesionales (trabajadores sociales, psicólogos, sociólogos, etc.) a un campo signado hasta entonces por el predominio casi exclusivo de los médicos. Los programas de formación y docencia, por su parte, comienzan más tarde, en las décadas de 1980 y $1990 .{ }^{24}$

La creación de la SAGG ocurrió en un contexto científico y académico propicio. Una prueba de ello fue la creación, en 1948, de un grupo dedicado al envejecimiento, por parte del Dr. Bernardo Houssay (1887-1971), Premio Nobel de Fisiología y Medicina en 1947 (Gastrón y Gastrón, 1998). El grupo se inspiraba en el Club de Investigaciones sobre Envejecimiento de Londres, dirigido por Korenchesky, quien organizó en 1949 una reunión con catorce países en la que Argentina, representada por Bernardo Houssay y E.F. Kraph, fue el único país latinoamericano invitado. ${ }^{25}$

El temprano surgimiento de la geriatría en la Argentina ocurrió en un contexto caracterizado por dos fenómenos convergentes. Por un lado, el envejecimiento de la población, visible desde el censo de 1914 e instalado dramáticamente en el centro de la escena por las preocupaciones natalistas de Alejandro Bunge. El censo nacional de población de 1947, que muestra que las personas de 60 años y más habían pasado de 4\% en 1914 a 6\% en 1947, confirma esa tendencia, aunque los valores muestran una población madura y no envejecida según la clásica definición de Naciones Unidas, que fijará un umbral más elevado (7\% de personas de 65 años y más). Como en otros casos, el peso del número debió contribuir a definir un contexto favorable pero en modo alguno decisivo para la emergencia de un saber. Por otra parte, debe incluirse el desarrollo científico impulsado en los años cuarenta por investigadores como

\footnotetext{
${ }^{24}$ La SAGG tenía como objetivo "propender a la investigación y al estudio de la fisiología, la patología de la senectud y de la senilidad, así como a la prevención y al tratamiento de las enfermedades de la vejez. Se ocupará también de los aspectos biológicos y sociales de la misma". Sobre el particular ver SAGG (2011) y Gastron y Gastron (1998).

${ }^{25}$ Cabe consignar asimismo que la Dra. Rebeca Gerschman (1903-1986), discípula de Houssay y candidata al Premio Nobel de fisiología y medicina en la década del 80, es considerada como una de las pioneras de la teoría de los radicales libres como causa del envejecimiento, paternidad disputada por el norteamericano Denhan Harman (Montiel y Cornejo, 2010).
} 
Bernardo Houssay y sus discípulos, cuya conexión con la creación de la SAGG apela por mayores estudios. ${ }^{26}$ En el mismo clima de ideas merecen mencionarse las preocupaciones del Ministro de Salud del gobierno peronista, Ramón Carrillo. Si bien el "Plan Sintético de Salud Pública, 1952-1958" no incluye especialidades geriátricas, Carrillo menciona entre los objetivos del plan la "prolongación de la vida útil del hombre", distinguiendo entre lo que denomina prolongación estadística (lucha contra las enfermedades crónicas invalidantes y la mortalidad infantil) y prolongación biológica (lucha contra la arterioesclerosis y la vejez prematura). Para esta última incluye la acción del "Instituto Pro-Vida" o "Pro longevidad" en la órbita del Ministerio de Salud (Carrillo, 1951: 56-58 y 129). ${ }^{27}$

El desfasaje entre la emergencia de la pediatría y la geriatría, equivalente a lo ocurrido en el plano internacional es menos difícil de explicar debido a la importancia acordada a la reproducción de la población y al binomio madrehijo. La centralidad de la niñez, muy clara desde el siglo XIX debido a la asociación entre niñez y problemas sociales como el analfabetismo, la delincuencia y la pobreza, aumentó por las preocupaciones derivadas de la denatalidad, tanto en la variante puramente cuantitativa como en la eugenésica. No ocurría lo mismo con el envejecimiento que, como vimos a propósito de Bunge, fue invocado como argumento suplementario de las preocupaciones natalistas.

\section{La emergencia de derechos}

Los aspectos jurídicos de la vejez recibieron escasa atención por parte de los historiadores del derecho en razón de la menor impronta de la edad como criterio diferencial de derechos y obligaciones. A pesar de ello, pueden detectarse indicios de interés durante el período.

En materia laboral, por ejemplo, la principal referencia es la definición de inmigrante propuesta por la Ley de Inmigración y Colonización núm. 817, o Ley Avellaneda, sancionada el 19 de octubre de 1876 por el Congreso Nacional. Además de criterios laborales (ocupaciones ejercidas) y migratorios (forma de arribo al país, antecedentes penales, datos de salud), la ley fijó una edad máxima de 60 años para ser reconocido como inmigrante, salvo en el caso de los jefes de familia. Los 60 años propuestos, que anticipan parcialmente las edades jubilatorias de mediados del siglo siguiente, coinciden con otros registros como el demográfico y el propuesto por la psicología. Si bien la ley prescribía penas

\footnotetext{
${ }^{26}$ Redondo (2007: 164) sostiene que la SAGG fue creada por influencia de Houssay, quien fue además uno de sus miembros fundadores (Fustinoni, 2010: 130).

${ }^{27}$ El interés de Carrillo por la vejez remonta a su juventud ya que en 1929 publicó un artículo titulado "Vida y obra sobre la personalidad de Marinesco", neurólogo rumano que elaboró una doctrina sobre la vejez. Sobre las ideas políticas y la obra de Carrillo ver: Ramacciotti (2009).
} 
para los capitanes de buques que violaran la normativa, las prácticas sobre el particular fueron mucho más permisivas. ${ }^{28}$

En el caso del derecho penal, las Siete Partidas castellanas constituyen el punto de inicio obligado para el análisis. Redactadas en el siglo XIII, las Partidas adjudican al anciano un mayor discernimiento y experiencia que a otras edades de la vida $\mathrm{y}$, por tanto, mayor carga, tanto en lo relativo a la culpabilidad como a la aplicación de las penas ("más cruelmente debía escarmentarse al siervo que al libre, al hombre vil que al hidalgo, al mancebo que al mozo y al viejo que al mancebo"'). ${ }^{29} \mathrm{El}$ período independiente supuso cambios importantes en relación a esa tradición. Por un lado, la igualación de la responsabilidad de los ancianos con la vida adulta. Por otro, la incorporación progresiva de criterios de reducción de la pena a partir de ciertas edades. En lo que hace a la responsabilidad penal, por ejemplo, el criterio dominante fue que la vejez no proporciona excusas aunque puede ser motivo de atenuantes según la apreciación del juez ante cada caso individual, como lo estipula Carlos Tejedor (1817-1903) en su clásico curso de derecho criminal de 1860:

"La vejez no escusa entre nosotros, si bien debe colocarse en las circunstancias atenuantes, cuya apreciación toca al juez. No habría tampoco razón en elevar la vejez a la categoría de escusa. La edad, por avanzada que sea, no es incompatible con la criminalidad. Por el contrario, la vejez que no es la imbecilidad tiene más bien en su contra la experiencia de los años. Otra cosa es la calidad del castigo. En la vejez, ciertas penas tenderían una excesiva gravedad, y la muerte no significa nada, dice un escrito, en una época en que la naturaleza abre la tumba delante del hombre" (Tejedor, 1860: I, 64).

Cuando incluyen la edad, los debates sobre la imputabilidad remiten solamente a la edad de inicio de la responsabilidad penal (10 años y medio en la época de Tejedor) y a la menor pena que pueden recibir los niños y jóvenes entre los 10 años y medio y los 17.

En lo que hace a la aplicación de las penas, el Proyecto Tejedor de Código Penal, que retoma las ideas de su curso de derecho criminal, propone una reducción a partir de los 70 años: "La edad avanzada del culpable no producirá efecto sino después de los setenta años y ese efecto consistirá solo en conmutarle la pena de muerte por penitenciaria por el tiempo de vida que le

\footnotetext{
${ }^{28}$ Los 60 años como límite para ser considerado inmigrante aparecen en los artículos 12 y 32 de la mencionada ley. Los partes consulares de la primera mitad del siglo XX sugieren, sin embargo, que la proporción de inmigrantes rechazados era prácticamente despreciable (comunicación personal de Silvia Di Liscia). En 1923, el gobierno radical elaboró un ambicioso proyecto de modificación de la ley migratoria, finalmente no aprobado, que proponía una edad máxima de 55 años.

29 Partida Séptima, citada por Rivarola (1910: 453).
} 
falte o en dispensarle de los trabajos forzosos de la de presidio" (Artículo 8). ${ }^{30}$ Idéntico criterio de reducción de la aplicación de la pena ("ser menor de 18 y mayor de setenta") aparece en referentes jurídicos del Centenario como Rodolfo Rivarola (1910: 466) y Alberto Stucchi (1916).

Este último autor resulta de interés porque busca aunar los aspectos jurídicos con los psicológicos mediante la distinción de tres estados de vejez: el estado normal, que no es excusa ni agravante (aunque "la presunción de mayor discernimiento pesa sobre él", en cursiva en el original); el patológico, afectado por la demencia senil, por ejemplo, y susceptible de los atenuantes propios de la enfermedad mental, y el mixto ("ancianos prematuros, sin ser tan entrados en años, [que] se encuentran tempranamente agotados por el trabajo, los placeres o las desgracias, es decir, quebrantados físicamente y con el espíritu deprimido"), (Stucchi, 1916: 370 y 372, respectivamente). Este último estado, en el que se observa la influencia progresiva de la psicología, en particular la de Ingenieros, cuyo capítulo sobre la vejez niveladora cita con detalle, no invalida según el autor la imputabilidad penal pero permitiría la aplicación de la "doctrina de la responsabilidad proporcional", es decir la atenuación de la culpabilidad cuando las facultades mentales se hallan disminuidas, y la exoneración total en caso de demencia senil. A pesar de estos matices, el criterio de atenuación de la pena es la condición mental y no la edad, ya que "la mente que ha guiado a la Legislación Argentina para juzgar las acciones de los ancianos no es la de la responsabilidad proporcional como lo hace al referirse a los menores e incapaces" (Stucchi, 1916: 374). ${ }^{31}$ Otro punto original es su propuesta de incluir al estado mixto, no contemplado en la legislación argentina. Su visión se aplica al derecho civil, más que al penal, para el que propone la creación de algún tipo de "tutela especial" que permita a los ancianos "un ejercicio limitado de su derechos, semejante por ejemplo, a la de los menores emancipados. Es decir, un estado civil intermedio entre el libre ejercicio de todos los derechos y la interdicción absoluta" (Stucchi, 1916: 375). La tutela buscaba proteger al anciano del potencial engaño de parientes $u$ otras personas, sobre todo en temas que

\footnotetext{
${ }^{30} \mathrm{El}$ artículo mencionado se basaba en el Código de Baviera (Tejedor, 1866: I. 183). Si bien el proyecto de Tejedor no fue aprobado por el congreso nacional se mantuvo como código aprobado por las provincias (Rivarola, 1910: 453). Un tema que requiere investigaciones sistemáticas es el de los delitos cometidos por mayores de 60 años tanto en términos estadísticos como judiciales (estrategias de defensa y penas recibidas). Un indicador de su débil influencia es que los cuadros estadísticos de causas judiciales por edad utilizan una única clase para las personas de 60 años y más, categoría que reunía al 1,5\% de los acusados en 1864, proporción menor que la que ese grupo de edad tenía en la población total (Hudson, 1865: I: 498). La ya mencionada tesis de Murguiondo (La infancia y la vejez ante la medicina legal), que incluye datos de la Cárcel Penitenciaria de Buenos Aires, confirma el escaso peso de los ancianos (60 años y más) entre los delincuentes de la ciudad durante el bienio 1886-1887.

${ }^{31}$ La distinción entre los estados normal, patológico y mixto es tomada del francés Henri Legrand Du Saulle (1830-1886), psiquiatra y especialista en medicina legal, y aparece también en la tesis de Murguiondo de 1887.
} 
pudieran importar un perjuicio económico. Más claro aún, si bien la curatela se hallaba prevista en el Código Civil para los casos de incapacidad (sin distinción alguna de la edad), Stucchi propone crear una figura específica de tutela para los viejos, ya que asume que los casos de discapacidad mental son mayores en ellos que en la edad adulta. Más allá de esas intenciones, la propuesta puede interpretarse también como un indicio de la asociación creciente entre vejez e incapacidad.

Finalmente, el Código Penal de 1921 ratifica las evoluciones precedentes en temas tales como la no imputabilidad de los menores de 14 años (art. 36); la gradación de penas entre los 14 y los 18 años (arts. 37-39); la no consideración de la edad avanzada como causa de inimputabilidad; la atenuación de los trabajos en prisión para los hombres de más de 60 años (art. 7) y, en el caso de penas de menos de seis meses, la prisión domiciliaria para los mayores de 60 años (art. 10). La edad es considerada una circunstancia atenuante o agravante entre muchas otras (arts. 40-41) sin referencia a ninguna edad particular, salvo en los menores. En sentido análogo, no se prevén medidas sobre la vejez abandonada, como si ocurre con la niñez (art. 106). ${ }^{32}$ En suma, y al igual que en otros casos nacionales, "la vejez no tiene efectos" (Pollet, 2001-2003: 44), salvo en lo relativo a la aplicación de las penas, reducidas a partir de cierta edad (70 en el caso francés, 60 en el argentino) por razones humanitarias.

Al igual que en medicina, las tesis doctorales en derecho y ciencias sociales del período 1827-1919 (3.742 en total) no se interesan en la vejez sino en las mujeres y, sobre todo, los niños, a quienes se consagran estudios específicos, como la protección de la infancia o la obligación de los padres hacia los hijos. La importancia de la familia para el sistema social explica asimismo los trabajos sobre filiación (hijos naturales, por ejemplo) y patria potestad; matrimonio, divorcio y adulterio; condición jurídica de la mujer; infanticidio y aborto, etc. Si bien existen algunas tesis sobre jubilaciones y seguro social (6 en total) su impacto en el universo de tesis es insignificante. Una vez más no se detectan tesis específicas sobre la vejez, capítulo indispensable en los manuales de derecho del período, pero sin duda poco atractivo para los futuros profesionales.

La estabilidad de la evolución jurídica evocada contrasta con las significativas innovaciones ocurridas en el plano constitucional durante la década del cuarenta. En un contexto marcado por la notable expansión de la cobertura jubilatoria, por el otorgamiento de los primeros subsidios a la vejez y por la creación de hogares de ancianos, entre otras medidas impulsadas por el

32 Si bien el código civil prevé que "los hijos deben respeto y obediencia a los padres" y "están obligados a cuidarlos en su ancianidad, en el estado de demencia o enfermedad, y a proveer a sus necesidades en todas las circunstancias de la vida, en que les sean indispensables sus auxilios" (art. 266), el código penal no establecía penas sobre el incumplimiento de esas obligaciones. 
gobierno peronista, la reforma constitucional de 1949 supuso un cambio sustantivo en la materia al darle rango constitucional a los Derechos de la Ancianidad proclamados por la Fundación de Ayuda Social Eva Duarte de Perón el 28 de agosto de 1948. ${ }^{33}$ Los Derechos de la Ancianidad (Decreto 32.138/48) tuvieron un significativo derrotero tanto a nivel internacional como doméstico. En el primer caso, fueron presentados ese mismo año en las Naciones Unidas, convirtiéndose en el primer intento internacional de establecer una declaración de los derechos de las personas mayores. La propuesta argentina fue comunicada al Consejos Económico y Social para su examen e informe a la Asamblea General, pero terminó diluyéndose. A esta iniciativa pionera de la Argentina le sucedieron otras tres, recién durante la década de 1990, que tampoco prosperaron (Huenchan, 2013). ${ }^{34}$

En el plano interno, los Derechos de la Ancianidad fueron incorporados sin modificaciones en el capítulo III de la Constitución de 1949, que consta del único y extenso artículo 37 sobre "derechos especiales", titulado los "Derechos del trabajador, de la familia, de la ancianidad y de la educación y la cultura". Salvo los dos últimos aspectos, que remiten a dimensiones de intervención más que a sujetos de derecho, el capítulo constituye un todo coherente ya que los derechos del trabajador (artículo 37, I, 7) incluyen el "derecho a la seguridad social" en "los casos de disminución, suspensión o pérdida de su capacidad para el trabajo". La incorporación de la seguridad social y, por extensión, los problemas más generales de la vejez, fue defendida en el debate constituyente de 1949 por el jurista Arturo Sampay, uno de los principales teóricos de la reforma constitucional, quien abrevaba en la tradición del nacionalismo católico y en encíclicas como Quadragesimo Anno (Dvoskin, 2015: 145-146). ${ }^{35}$

33 La incorporación de los derechos de la ancianidad fue acompañada de otras medidas relevantes como la expansión del sistema jubilatorio y la ley 13.478 de octubre de 1948 que reglamentó un régimen de pensiones asistenciales para la vejez con un monto del $70 \%$ de la pensión mínima derivada de la jubilación ordinaria. Según Redondo (2007: 165-166), la ley constituye el "primer antecedente normativo a través del cual se reconocen, en nuestro país, deberes estatales en la cobertura de las personas con recursos insuficientes". La ley recién fue aplicada en 2003.

${ }^{34}$ Los intentos de la década de 1990 no prosperaron aunque la propuesta presentada de manera conjunta por la República Dominica y la Federación Internacional de la Vejez avanzó en la elaboración de los Principios de las Naciones Unidas en favor de las Personas de Edad en cinco temas básicos, independencia, participación, cuidados, autorrealización y dignidad (Huenchan, 2013: 3-4).

${ }^{35}$ La declaración de los derechos de los ancianos nació de la propia Eva Perón (Navarro, 2018, 244-245 y sobre todo 276). En su alocución Sampay incluye los derechos de los ancianos en el marco más general de la defensa de la "unidad económica familiar" en contra de lo que denomina "individualismo jurídico" liberal. Al igual que las restantes políticas sociales, los Derechos de la Ancianidad fueron ampliamente difundidos por la propaganda peronista y dieron lugar a la creación del Parque homónimo, inaugurado por el gobernador Domingo Mercante, con la presencia de Perón y Eva el 24 de febrero de 1950 en terrenos expropiados a la 
Los derechos de la ancianidad (artículo 37, III, incisos 1 a 10) incluyen el derecho a la asistencia ("protección integral por cuenta y cargo de su familia. En caso de desamparo, corresponde al Estado proveer dicha protección"), la vivienda, la alimentación, el vestido, el cuidado de la salud física y de la salud moral, el esparcimiento, el trabajo, la tranquilidad y el respeto. El artículo mezcla derechos comunes a cualquier edad (el derecho a la vivienda, por ejemplo) con otros más específicos para los adultos mayores (como la protección de la familia). Asimismo, alterna temas legislables o de potencial reglamentación y cumplimiento con enunciaciones de naturaleza puramente moral (el vestido debe ser "decoroso"; las "expansiones espirituales, concordes con la moral y el culto"; "el derecho de gozar [...] de un mínimo de entretenimientos para que pueda sobrellevar con satisfacción sus horas de espera" debe ejercerse "mesuradamente"; "el anciano tiene derecho al respeto y consideración de sus semejantes", etc.). Algunas de estas consideraciones no escapaban a difundidos estereotipos sobre la vejez y, en tanto tales, continuaban tópicos de larga data como la condena a la desmesura. Otros en cambio, como el derecho al trabajo ("La ocupación por medio de la laborterapia productiva ha de ser facilitada. Se evitará la disminución de la personalidad”) preanuncian la visión más actual del envejecimiento activo.

No es necesario enfatizar la influencia del constitucionalismo social y del pensamiento católico en el texto constitucional de 1949, hecho señalado por muchos autores. Sin embargo, y siguiendo la contemporánea exégesis de Díaz de Guijarro (1953: 303-304), la legislación sobre familia y ancianidad no debe ser interpretada en un sentido dogmático en la medida que la "dignificación y el amparo del grupo no es un concepto privativo de ninguna escuela filosófica ni de ningún credo religioso". Tras el derrocamiento de Perón en 1955, la reforma constitucional de 1957 derogó la constitución de 1949 pero incorporó muchos de los derechos sociales de la época peronista en el artículo 14 bis, en particular el derecho a la seguridad social y la jubilación y pensiones móviles, pero sin referencias a los ancianos en tanto tales. ${ }^{36}$

El tema de los ancianos recién reaparecerá explícitamente en la Reforma de la Constitución Nacional de 1994, que otorgó rango constitucional a la Convención sobre los Derechos del Niño, y estableció entre las atribuciones del Congreso la de "legislar y promover medidas de acción positiva [...] en particular respecto de los niños, las mujeres, los ancianos y las personas con discapacidad" (art. 75, incisos 22 y 23). Como puede apreciarse, tanto en el plano internacional como en el doméstico, el interés por los derechos de los

familia Pereyra Iraola.

36 La declaración de los Derechos de la Ancianidad es analizada por Pérgola (2004: 101-102), quien la califica de "lírica" por su no aplicación ulterior, y sobre todo por Mariluz (2009). Sobre la constitución de 1949 y los derechos constitucionales de los ancianos ver: Benente (2019) y Novelli (2006), respectivamente. 
ancianos se manifestó a partir de la década de 1990, en la que comienza a desarrollarse el "derecho de la ancianidad" como una nueva -e incipienterama del derecho (Dabove Caramuto et al., 2008) pero sin que las declaraciones constitucionales se manifiesten en normativas concretas.

No es nuestro objetivo evaluar la declaración de la ancianidad en términos constitucionales. Antes bien, en términos más propiamente históricos, importa destacar que, más allá de las limitaciones expuestas, el texto de 1949 constituyó un avance pionero y trascendente en relación a la percepción de la vejez como clase de edad con derechos específicos. Este avance es tanto más significativo si se considera que textos internacionales contemporáneos, como la Declaración Universal de los Derechos del Hombre (Naciones Unidas, Paris, 10 de diciembre de 1948), la Declaración de principios sociales de América (Conferencia Interamericana sobre Problemas de la Guerra y la Paz, México, 7 de marzo de 1945) y la Declaración Americana de los derechos y deberes del Hombre (IX Conferencia Internacional Americana, Bogotá, 2 de mayo de 1948) incluyeron la protección de la madre y el niño de manera específica mientas que la vejez aparece solo en lo relativo a la subsistencia económica. ${ }^{37}$ La misma precocidad del caso argentino aparece cuando se realizan comparaciones con otros países, como la Older American Act de 1965. Si bien existen declaraciones de principios, como los "Principios de las Naciones Unidas en favor de las personas de Edad" (Asamblea General de Naciones Unidas, resolución 46/1991) en instrumentos que se multiplican durante los años noventa, hasta la fecha no hay ninguna convención o tratado sobre la ancianidad dentro del sistema de Naciones Unidas.

Las claras limitaciones operacionales de los derechos de la ancianidad del peronismo, por otra parte, no desentonan con las declaraciones internacionales posteriores, como los recién mencionados Principios de 1991, cuyo contenido performativo y genérico es igualmente evidente. Los derechos de la ancianidad de la constitución peronista de 1949 corren, en suma, dos riesgos que deben ser evitados: tomar al pie de la letra un conjunto de prescripciones generales pero de escaso efecto; descartar, en virtud de esa misma generalidad, la novedad que supone su enunciado en términos socio-históricos cuando se la incluye en el marco internacional.

\footnotetext{
${ }^{37}$ El análisis constitucional comparado propuesto por Díaz de Guijarro (1953: 352-353) muestra que eran escasas las constituciones que consagraban el amparo de los ancianos y más numerosas las que incluían referencias a la previsión económica contra las consecuencias de la vejez. Sobre Díaz de Guijarro, abogado y eugenista, ver: Vallejo y Miranda (2014).
} 


\section{Conclusiones}

Hacia fines de la primera mitad del siglo XX un conjunto de saberes, de diferente peso y naturaleza, posibilitó la cristalización progresiva de una imagen de la vejez y del envejecimiento que desde entonces ganó progresivamente terreno en la agenda científica y política internacional. En el caso argentino, la construcción social de la vejez fue el fruto de factores internacionales y vernáculos.

Entre los primeros se destaca el temprano desembarco de la teoría del envejecimiento, formulada por Alfred Sauvy en 1928 y consagrada por Naciones Unidas en la inmediata posguerra. Las filiaciones intelectuales entre la obra de Alejandro Bunge y sus mentores europeos son múltiples. Su obra derivó, como ha sido dicho, de la similitud del caso argentino con el francés en un aspecto sustantivo: la baja temprana de la natalidad, con su consiguiente efecto sobre el envejecimiento demográfico. Esa similitud inicial fue acompañada de diferencias relevantes, como el alto peso de la inmigración en la Argentina, llamada a acelerar el envejecimiento en el mediano plazo tras la detención del flujo en 1930 y, sobre todo, el devastador efecto de la Gran Guerra en el caso europeo. La ausencia de este último factor muestra hasta qué punto las sombrías predicciones bungeanas derivaban de elementos ideológicos provenientes del eugenismo y del nacionalismo católico pero también de un clima de ideas internacional -como el de la decadencia de la raza blanca- que facilitaba la reproducción más o menos automática de esquemas operacionales y visiones sociales generales. La teoría del envejecimiento favoreció la propaganda natalista, de la que constituyó inicialmente un argumento particularmente pedagógico, pero también permitió condensar un conjunto de elementos negativos sobre la vejez. Esos elementos incluían desde lo económico hasta lo cultural y, por su misma variedad y alcance, tenían distinto nivel de prueba. Cualquiera sea el caso, retomaron estereotipos de larga data sobre y contribuyeron, al mismo tiempo, a reforzar la imagen negativa sobre los ancianos. Las visiones sobre la vejez individual, en términos micro, y el envejecimiento de la población, en términos macro, a pesar de sus evidentes diferencias conceptuales, se reforzaron mutuamente mediante una articulación llamada a tener larga vigencia. En ese contexto cabe al autor de Una nueva Argentina el indudable mérito de la incorporación sistemática de la teoría al debate demográfico argentino a pesar del catastrofismo de algunos de sus postulados extrademográficos.

En lo relativo a los saberes médicos, la hipótesis habitual sobre el caso europeo postula que la geriatría "ofrecía un enfoque de la realidad humana que desembocaba en una visión pesimista del problema, quizás no tanto de la vejez en sí cuanto de los ancianos como colectivo" (Bourdelais et al., 2007: 47). El trabajo con viejos en asilos y hospitales, en los que la asociación con diversas formas de insania, desamparo y pobreza era, por definición, estrecha $\mathrm{y}$ 
diferente a la de la inmensa mayoría de ancianos no institucionalizados, favoreció naturalmente esas imágenes negativas. La hipótesis debe matizarse ya que el caso argentino testimonia más bien la marginalidad o incluso insignificancia de las investigaciones y tesis sobre la vejez, cuanto menos hasta mediados de los años cuarenta del siglo XX. Los saberes no reflejan desde luego las prácticas médicas y sanitarias pero las evidencias disponibles (el completo Plan del Ministro Carrillo, por ejemplo) confirman la escasa visibilidad de los viejos en tanto población objeto de reflexiones y tratamientos específicos. Distinto fue el caso de la psicología que, en virtud de su menor solidez experimental, fue mucho más permeable a los estereotipos propios del modelo de disminución de la vejez, muchos de los cuales repetían -en idénticos términos- consideraciones morales y filosóficas inmemoriales. Si la geriatría contribuyó a reforzar las imágenes negativas sobre los viejos, ello ocurrió a partir de la segunda mitad del siglo, cuando el avance de esos saberes, tanto en el plano científico como mediático, devino más importante. La aparición más tardía de la geriatría en relación a la más pujante pediatría, por su parte, fue el reflejo local de la evolución de los saberes internacionales en la materia y del peso diferencial de ambos grupos de edad en la agenda política y sociodemográfica, aspecto reforzado en la Argentina por las visiones natalistas y por el envejecimiento de la población, aunque las vinculaciones efectivas entre saberes demográficos y médicos distan de ser evidentes.

Por último, los saberes jurídicos tuvieron una estabilidad semejante. La vejez no constituyó, en efecto, un elemento central en términos civiles o penales, salvo en lo relativo a la reducción de la aplicación de las penas en las edades avanzadas, principio también tributario de la experiencia internacional. La ruptura con el pasado radica en la consideración del viejo como un ciudadano igual a los demás, es decir no susceptible de agravantes (como en las Siete Partidas) o atenuantes derivados de la edad, aun cuando algunos atenuantes (la reducción de la capacidad psicológica o intelectual, por ejemplo) pudieran ser más frecuentes en esa edad que en otras. La declaración de los Derechos de la Ancianidad y su incorporación a la constitución nacional durante el peronismo constituye en cambio una originalidad argentina en la materia y una ruptura de notable precocidad en relación al plano internacional, que incorpora reflexiones sobre el particular a partir de la década de 1990.

Visto el tema en clave cronológica, hacia mediados de siglo se asiste a una simultaneidad, jalonada por el desembarco de la teoría del envejecimiento (1940), la Declaración de los Derechos de la Ancianidad (1948) y su incorporación a la Constitución Nacional del año siguiente y la creación de la Sociedad Argentina de Gerontología (1951). Más allá de la diferente importancia de estos hechos, la década del cuarenta, definida en sentido amplio, marca un punto de consolidación decisivo en la invención social de la vejez. Simultaneidad no significa desde luego causalidad ya que, hasta donde lo 
permite afirmar el estado del arte, los saberes mencionados carecieron de vasos comunicantes significativos. Si la evolución demográfica estaba claramente presente en la reflexión bungeana del envejecimiento, por ejemplo, esta no parece constituir un insumo necesario de los avances experimentados en los otros campos. Antes bien, la simultaneidad parece derivar sobre todo de la recepción de saberes internacionales, de distinta profundidad temporal, que hacen eclosión en esos años, aspecto muy evidente, como vimos, en la simultaneidad de las creaciones de sociedades de geriatría. Si la expresión clima de época es válida, la emergencia de la vejez y del envejecimiento en nuestro país constituye un caso paradigmático, aunque ciertamente no único.

La puesta en conjunto de los tres campos permite otra reflexión de interés. Mientras los saberes médicos y la teoría demográfica retoman y potencian una visión negativa del envejecimiento individual y colectivo (reforzándose mutuamente como lo ha mostrado Bourdelais, 1997), los saberes jurídicos evolucionaron en nuestro país hacia el reconocimiento temprano de derechos específicos de los ancianos.

\section{Bibliografía}

Ariès, Philippe (1983). “Une histoire de la vieillesse? Entretien avec Philippe Ariès",en Communications, 37, pp. 47-54.

Benente, Mauro (comp.) (2019). La constitución maldita. Estudios sobre la reforma de 1949, José C. Paz: Edumpaz.

Biernat, Carolina (2007). ¿Buenos o útiles? La política inmigratoria del peronismo, Buenos Aires: Biblos.

Bourdelais, Patrice (1997). L'âge de la vieillese. Histoire du vieillissement de la population, Paris: Odile Jacob.

Bourdelais, Patrice; Gourdon, Vincent; Viret, Jérôme-Luther (2007). "La vejez en Francia, siglos XVII-XX. Entre las regulaciones familiares, las representaciones sociales y los intereses científico-políticos", en Dubert García, Isidro; Hernández Borge, Julio; Andrade Cernada, José M. (eds.) Vejez y envejecimiento en Europa Occidental, Universidad de Santiago de Compostela, pp. 31-60.

Bourlière, François (1979). "Histoire de la gérontologie", en Poulet, Jacques; Sournia, Jean-Charles, Martiny, Marcel (dirs.) Histoire de la médecine, de la pharmacie, de l'art dentaire et de l'art vétérinaire, Paris: Albin Michel, Tomo VI, pp. 83-109.

Bunge, Alejandro (1984) [1940].Una nueva Argentina, Buenos Aires: Hyspamérica. 
Candioti, M. (1920). Bibliografía doctoral de la Universidad de Buenos Aires y Catálogo cronológico de las tesis en su primer centenario. 1821-1920, Buenos Aires: Talleres Gráficos del Ministerio de Agricultura de la Nación.

Carbajo Vélez, María del Carmen (2008). "La historia de la vejez", en Ensayos,18, pp. 237-254.

Carrillo, Ramón (1951). Plan Sintético de Salud Pública 1952-1958, Buenos Aires: Honorable Cámara de Diputados de la Nación, Dirección de Información Parlamentaria.

Cesano, José Daniel (2016). Medicalizando la niñez delincuente. Intervenciones psiquiátricas en la criminalidad infantil (Buenos Aires, Rosario, Córdoba, 1920-1940), Córdoba: Brujas.

Dabove Caramuto, María Isolina; Gonem Machello, Graciela; Nawojczyk, Érica; Novelli, Mariano; Prunotto, Mariana; Rodrigo, Fernando (2008). “Aportes para el pleno reconocimiento constitucional de los derechos de los ancianos", en $L a$ Ley, LXXII, (118), pp. 1-4.

Díaz de Guijarro, Enrique (1953). Tratado de derecho de familia, Buenos Aires: Tipográfica Editora.

Dvoskin, Nicolás (2015). “Del derecho a la economía: las principales referencias teóricas en la política de seguridad social argentina (1949-1983), en Estudios Sociales del Estado, núm. 1, pp. 139-168.

Faguet, Auguste (1926). La vieillese, Paris: Éditions Sansot.

Feller, Élise (2017). Du vieillard au retraité. La construction de la vieillesse dans la France du XXe siècle, Paris: L'Harmattan.

Fustinoni, Juan Carlos (2010). Mi padre. Osvaldo Fustinoni (1909-2000), Buenos Aires: Dunken.

Gastrón, Liliana; Gastrón, Gerardo (1998). “Medio siglo de gerontología en Latinoamérica", en Revista Española de Geriatría y Gerontología, 33 (5), pp. 309313.

González Bollo, Hernán (2004a). “La formación intelectual del ingeniero Alejandro Ernesto Bunge (1880-1913", en Valores en la sociedad industrial, núm. 59, pp. 36-43.

González Bollo, Hernán (2004b). “Alejandro Ernesto Bunge: ideas, proyectos y programas para la Argentina post-liberal (1913-1943)", en Valores en la sociedad industrial, núm. 61, pp. 61-74.

Gutton, Jean-Pierre (1988). Naissance du vieillard: Essai sur l'histoire du rapport entre les vieillards et la société en France, Paris: Aubier.

Henry, Louis (1987). "Perspectives et prévision", en INED Les projections démographiques, Paris: Presses Universitaires de France, Tomo I, pp. 3-11. 
Hudson, Damián (1865). Registro Estadístico de la República Argentina. 1864, Buenos Aires: Imprenta J.A. Berheim.

Huenchan, Sandra (2013). Los derechos de las personas mayores en el ámbito internacional, Santiago de Chile: CEPAL-CELADE.

Ingenieros, José (2006). El hombre mediocre, Buenos Aires: Centro Editor de Cultura.

Le Bras, Hervé (1991). Marianne et les lapins. L'obsession démographique, Paris: Pluriel.

Mariluz, Gustavo (2009). Estado, política y vejez. La política social para la tercera edad en Argentina desde el Virreynato del Río de la Plata hasta el año 2000, Buenos Aires: Gobierno de la Ciudad, Centro de Documentación de Políticas Sociales.

Montiel, Inés; Cornejo, Jorge Norberto (2010). “Gerschman, Houssay y la ciencia en Argentina", en Res Gesta, 48.

Navarro, Marysa (2018). Evita, Buenos Aires: Edhasa.

Novelli, Mariano (2006). Derechos constitucionales de los ancianos, Buenos Aires: Dunken.

Otero, Hernán (2004). "Sueños cifrados. Una arqueología de las proyecciones de población de la Argentina moderna", en Revista de Demografía Histórica, XXII, I, pp. 209-239.

Otero, Hernán (2006). Estadística y nación. Una historia conceptual del pensamiento censal de la Argentina moderna, 1869-1914, Buenos Aires: Prometeo.

Otero, Hernán (2017). "The Winter of Life. The Mortality of Old People in Tandil (Buenos Aires, Argentina), 1858-1914", en Annales de Démographie Historique, 133, 1, pp. 17-45.

Pérgola, Federico (2004). Historia de la salud social en la Argentina, Buenos Aires: Superintendencia de Servicios de Salud.

Pollet, Gilles (2001/2003). "La vieillese dans la littérature, la médecine et le droit au XIXème siècle: sociogenèse d'un nouvel âge de vie", en Retraite et Société, núm. 34, pp. 29-49.

Ramacciotti, Karina (2009). La salud pública del peronismo, Buenos Aires: Biblos.

Redondo, Nélida (2007). “Composición por edades y envejecimiento demográfico", en Susana Torrado (comp.) Población y bienestar en la Argentina del primero al segundo Centenario. Una historia social del siglo XX, Buenos Aires: EDHASA, Tomo II, pp. 139-175.

Reggiani, Andrés; González Bollo, Hernán (2007). “Dénatalité, 'crise de la race' et politiques démographiques en Argentine (1920-1940)", en Vingtième Siècle, 95, pp. 29-44. 
República Argentina, Dirección Nacional del Servicio Estadístico (1952). IV Censo General de la Nación 1947, Buenos Aires: Editorial Guillermo Kraft Ltda.

República Argentina, Dirección Nacional de Estadísticas y Censos (1956). Informe Demográfico de la República Argentina, 1944-1954, Buenos Aires: Editorial Guillermo Kraft Ltda.

Ribot, Théodule-Armand (1900). La psicología de los sentimientos, Madrid: Librería de Fernando Fe.

Rivarola, Rodolfo (1910). Derecho Penal Argentino, Madrid: Casa Editorial Hijos de Reus.

Rustoyburu, Cecilia (2019). La medicalización de la infancia. Florencio Escardó y la nueva pediatría en Buenos Aires, Buenos Aires: Biblos.

Sánchez Granjel, Luis (1999). Historia de la vejez. Gerontología, Gerocultura, Geriatría, Universidad de Salamanca.

Sánchez Salgado, Carmen (2005). Gerontología social, Buenos Aires: Espacio.

Sauvy, Alfred (1928-1929). "La population française jusqu'en 1956, essai de prévision démographique", Journal de la Société de Statistique de Paris, núm. 12, décembre 1928; núm. 1, janvier 1929.

Sociedad Argentina de Gerontología y Geriatría (2011). “Historia de la Sociedad Argentina de Gerontología y Geriatría (1951-2011)", en Revista Argentina de Gerontología y Geriatría, abril, pp. 8-21.

Sociedad Argentina de Pediatría (2011). 100 años. Sociedad Argentina de Pediatría, Buenos Aires: Ideográfica.

Stucchi, Alberto (1916). Manual de medicina legal, Buenos Aires: Imprenta de Obras de E. Spinelli.

Tejedor, Carlos (1860). Curso de Derecho Criminal, Buenos Aires: Imprenta Argentina.

Tejedor, Carlos (1866). Proyecto del Código penal para la República Argentina, Buenos Aires: Imprenta del Comercio del Plata.

Thane, Pat (2007). "La vejez en la historia inglesa", en Dubert García, Isidro; Hernández Borge, Julio; Andrade Cernada, José M. (eds.) Vejez y envejecimiento en Europa Occidental, Universidad de Santiago de Compostela, pp. 13-30.

Vallejo, Gustavo; Miranda, Marisa (2014). “Iglesia Católica y eugenesia latina: un constructo teórico para el control social (Argentina, 1924-1958)", en Asclepio, 66 (2), pp. 1-12. 